\title{
PENGARUH KAPUR TERHADAP KUAT GESER TANAH LEMPUNG
}

\author{
Nahesson Panjaitan \\ Dosen Pengajar Jurusan Pendidikan Teknik Bangunan, Fakultas Teknik, UNIMED, Medan \\ Surel : nahessonpanjaitan@gmail.com \\ Diterima : 08 November 2017; Disetujui : 17 November 2017
}

\begin{abstract}
ABSTRAK
Penelitian ini dilakukan untuk mengetahui pengaruh penambahan kapur terhadap peningkatan kuat geser tanah lempung. Contoh tanah yang digunakan dalam penelitian diambil dari daerah TarutungSibolga Km.11 yang memiliki tanah yang kurang baik untuk digunakan sebagai tanah dasar dalam jalan raya. Hal ini disebabkan tanah lempung memiliki sensitivitas yang tinggi terhadap perubahan kadar air, sehingga menyebabkan kuat geser tanah tersebut rendah.Untuk itu perlu dilakukan perbaikan tanah dengan penambahan kapur. Kapur merupakan salah satu material yang cukup efektif dalam perbaikan tanah. Efektivitas perbaikan tanah lempung dengan penambahan kapur dapat dilihat dari sifat mekanik tanah tersebut. Untuk mengetahui pengaruh kapur maka dilakukan dengan cara membuat variasi pencampuran kapur sebesar $0 \%, 5 \%, 10 \%, 15 \%$ dan $20 \%$. Hasil penelitian uji sifat mekanik diantaranya penambahan $5 \%$ kapur nilai kohesi dan sudut geser masing masing sebesar $1,28 \mathrm{~kg} / \mathrm{cm}^{2}$ dan 37,950, meningkat menjadi $1,44 \mathrm{~kg} / \mathrm{cm}^{2}$ dan 63,770 pada pencampuran kapur $20 \%$. Berdasarkan hasil penelitian menunjukkan penambahan kapur dapat meningkatkan nilai sudut geser dalam serta nilai kohesi tanah lempung.
\end{abstract}

Kata Kunci : kuat geser, kapur, tanah lempung

\begin{abstract}
This research was conducted to determine the influence of the addition of lime to increased shear of clay soil. Clay soil that use in experiment is taken on Tarutung-Sibolga road at km.11 th have a less good soil for use as a base in the foundation of the highway. This looks at the broken road subgrade and wavy. The problems caused by the soil clays have a high sensitivity to changes in water content, thus causing strong shear the soil is low. It needs to be done to repair the soil with addition of lime. Lime material is one that is quite effective in the improvement of land.The effectiveness of the improvements to the clays with the addition of limestone can be seen from the nature of the mechanical properties of the soil. To know the influence of lime against clay done by creating variations of mixing lime amounting to $0 \%, 5 \%, 10 \%, 15 \%$ and $20 \%$. The results show that the mechanical properties the lime addition of $5 \%$ the values of cohesion and corner shear respectively amounting to $1.28 \mathrm{~kg} / \mathrm{cm}^{2}$ and 37.950 , increased to $1.44 \mathrm{~kg} / \mathrm{cm}^{2}$ and 63.770 on mixing lime $20 \%$. Based on results of the research showed the addition of lime, can increase the shear degree and cohesion values of clay.
\end{abstract}

Keywords: Clay, Lime, Shear Strength

\section{Pendahuluan}

Tanah lempung merupakan partikel mineral yang berukuran lebih kecil dari 0,002 $\mathrm{mm}$. Partikel-partikel ini merupakan sumber utama dari kohesi di dalam tanah yang kohesif (Bowles, 1991). Lempung (clay) sebagian besar terdiri dari partikel mikroskopis dan submikroskopis yang berbentuk lempenganlempengan pipih dan merupakan partikelpartikel dari mika, mineral-mineral lempung (clay minerals), dan mineral-mineral yang sangat halus lainnya (Das, 1995). Umumnya 
tanah lempung sangat kurang menguntungkan dalam konstruksi teknik sipil.Hal ini disebabkan oleh kuat gesernya rendah dan kompresibilitas yang besar.

Sebagian besar tanah yang ada di Indonesia termasuk dalam kategori tanah lempung.Salah satunya tanah yang berada di daerah Tarutung Sibolga Km.11 tepatnyadi Desa Banuaji II, Kecamatan Adiankoting, Tapanuli Utara.Di daerah tersebut tanah lempungnya masih tergolong tanah lempung yang kurang baik apabila digunakan sebagai penopang pondasi bangunan konstruksi apapun terutama konstruksi jalan raya.Ini terlihat pada subgrade jalan yang pecah dan bergelombang.

Ada beberapa sifat - sifat tanah lempung yang perlu diperhatikan dalam suatu proyek bangunan, yaitu permeabilitas, pemampatan dan kuat geser, sedangkan sifat fisis, yaitu batas konsistensi, kadar air, ukuran butiran. Permasalahan yang biasanya timbul dari tanah lempung ini yaitu tingkat sensitifitasnya yang terlalu tinggi terhadap perubahan kadar air, sehingga perlu dilakukan perbaikan tanah, diantaranya dengan menggunakan kapur.

Alternatif yang dilakukan untuk perbaikan tanah lempung agar lebih stabil yaitu dengan penambahan kapur.Kapur yang digunakan dalam penelitian ini, jenis kapur Tohor yang biasa digunakan sebagai bahan bangunan.Kapur telah banyak di teliti dalam pemanfaatannya sebagai bahan untuk perbaikan tanah, dan hasilnya dapat meningkatkan daya dukung tanah.

Untuk mengetahui pengaruh pencampuran kapurdengan tanah lempung maka dilakukan dengan cara membuat variasi pencampuran kapur sebesar 0\%,5\%, 10\%, 15\% dan $20 \%$, sehingga mendapatkan nilai yang maksimal terhadap peningkatan kuat geser tanah dengan melakukan uji mekanis tanah lempung. sifat mekanis itu sendiri yaitu uji kuat geser tanah (Direct Shear).

Berdasarkan latar belakang masalah diatas dapat dirumuskan beberapa masalah antara lain sebagai berikut :

1. Apa jenis tanah lempung Tarutung Sibolga

Km.11 berdasarkan sistem klasifikasi

tanah?

2. Bagaimana pengaruh penambahan kapur terhadap peningkatan kuat geser tanah lempung?

Batasan masalah dalam penelitian ini meliputi:

1. Penelitian menggunakan tanah yamg diambil dari Desa Banuaji II, Kecamatan Adiankoting, Tapanuli Utara.
2. Identifikasi Campuran kapur yang digunakan adalah 5\%,10\%, 15\%, dan $20 \%$ dengan waktu pemeraman 10 hari.

3. Batasan penelitian yang dilakukan dilaboratorium yaitu Uji kuat geser langsung (direct shear test)

Sehingga tujuan penelitian ini adalah mengetahui jenis tanah lempung Tarutung Sibolga Km.11 berdasarkan sistem klasifikasi tanah. Serta mengetahui peningkatan nilai kuat geser pada tanah lempung terhadap variasi kapur 5\%, 10\%, 15\%, dan $20 \%$.

\section{Kajian Pustaka}

2.1 Tanah Lempung

Tanah lempung merupakan agregat partikel - partikel berukuran mikroskopik dan submikroskopik yang berasal dari pembusukan kimiawi unsur - unsur penyusun batuan, dan bersifat plastis dalam selang kadar air sedang sampai luas (Terzaghi, 1987). Permeabilitas lempung sangat rendah, bersifat plastis pada kadar air sedang. Pada keadaan air yang lebih tinggi tanah lempung akan bersifat lengket (kohesif) dan sangat lunak. (Terzaghi, 1987)

Tanah lempung dan mineral lempung adalah tanah yang memiliki partikel - partikel mineral tertentu yang menghasilkan sifat - sifat plastis pada tanah bila dicampur dengan air (Grim, 1953).

Menurut Hardiyatmo (2002) sifat - sifat yang dimiliki tanah lempung adalah sebagai berikut :

1. Ukuran butir halus, kurang dari 0,002 mm

2. Permeabilitas rendah

3. Kenaikan air kapiler tinggi

4. Bersifat sangat kohesif

5. Kadar kembang susut yang tinggi

6. Proses konsolidasi lambat.

Partikel - partikel mineral dari lempung merupakan sumber utama dari kohesi di dalam tanah yang kohesif (Bowles, 1991).

\subsection{Sifat - Sifat Fisik}

\section{A. Analisa Distribusi Butir (Grain size analysis)}

Distribusi ukuran butiran kasar ditentukan dengan metode pengayakan atau sieve analysis untuk ukuran partikel - partikel berdiameter lebih besar dari 0,075 mm. Sedangkan untuk tanah berbutir halus ditentukan dengan metode sedimentasi pengendapan dengan alat hidrometer untuk ukuran partikel - partikel berdiameter lebih kecil dari 0,075 $\mathrm{mm}$. 
B. Batas - Batas Konsistensi

Atterberg memberikan cara untuk menggambarkan batas - batas konsistensi dari tanah berbutir halus dengan mempertimbangkan kandungan kadar airnya (Holtz dan Kovacs, 1981). Konsistensinya tanah dibedakan menjadi 4 keadaan dasar : padat, semi padat, plastis, cair.

1. Transisi dari padat kesemi padat disebut batas susut (shrinkage limit) $=S_{L}=W_{S}$. yaitu kadar air maksimum ketika pengurangan kadar air tidak akan menyebabkan perubahan volume dari massa tanah.

2. Transisi dari semi padat ke plastis disebut batas plastis (plastic limit) $=\mathrm{P}_{\mathrm{L}}=$ $W_{P}$. yaitu besar kadar air dimana tanah apabila digulung sampai diameter $3 \mathrm{~mm}$ tanah akan retak - retak.

3. Transisi dari plastis ke cair disebut batas cair (liquid limit) $=\mathrm{L}_{\mathrm{L}}=\mathrm{W}_{\mathrm{L}}$ yaitu kadar air dimana tanah akan mengalir akibat berat sendiri. Tanah dalam keadaan batas cair diperlukan kurang lebih 25 kali pukulan. (Santosa dkk, 1998).

Klasifikasi jenis tanah berdasarkan indeks plastisitasnya dilihat pada Tabel 1.

Tabel 1. Indeks Plastisitas Tanah

\begin{tabular}{|c|c|c|c|}
\hline PI & Sifat & $\begin{array}{l}\text { Macam } \\
\text { Tanah }\end{array}$ & Kohesi \\
\hline 0 & $\begin{array}{l}\text { Non - } \\
\text { plastis }\end{array}$ & Pasir & \\
\hline$<7$ & $\begin{array}{l}\text { Plastisitas } \\
\text { Rendah }\end{array}$ & Lanau & $\begin{array}{l}\text { Kohesif } \\
\text { sebagian }\end{array}$ \\
\hline $7-17$ & $\begin{array}{l}\text { Plastisitas } \\
\text { Sedang }\end{array}$ & $\begin{array}{l}\text { Lempung } \\
\text { Berlanau }\end{array}$ & Kohesif \\
\hline$>17$ & $\begin{array}{l}\text { Plastisitas } \\
\text { tinggi }\end{array}$ & Lempung & Kohesif \\
\hline
\end{tabular}

\subsection{Sifat - Sifat Mekanik}

\section{A. Pemadatan Tanah (Proctor Standar)}

Pemadatan adalah peristiwa bertambahnya berat volume kering oleh beban dinamis. Tigakomponen yang mempengaruhi pemadatan tanah, yaitu sifat dasar dari tanah yang tergantung darijenis mineral dan komposisinya dalam tanah, kadar air tanah, dan energi pemadat yang diberikan.

Percobaan pemadatan di laboratorium dilaksanakan untuk memperoleh kadar air optimum dan berat isi kering maksimum. Sedangkan menurut Craig (1989), pemadatan (compaction) adalah proses naiknya kerapatan tanah dengan memperkecil jarak antar partikel sehingga terjadi reduksi volume udara dan tidak terjadi perubahan volume air yang cukup berarti pada tanah ini. Umumnya, makin tinggi derajad pemadatan, makin tinggi pula kekuatan geser dan makin rendah kompresibilitas tanah

Manfaat dari pemadatan tanah adalah memperbaiki beberapa sifat teknik tanah (Santosa dkk. 1998) adalah:

1. Memperbaiki kuat geser tanah yaitu menaikkan nilai $\emptyset$ dan C (memperkuat tanah).

2. Mengurangi kompresibilitas yaitu mengurangi penurunan oleh beban.

3. Mengurangi permeabilitas yaitu mengurangi nilai $\mathrm{k}$

4. Mengurangi sifat kembang susut tanah (lempung)

\section{B. Kuat Geser Tanah}

Kekuatan geser tanah menurut Hardiyatmo (2002) merupakan gaya perlawanan yang dilakukan oleh butir - butir tanah terhadap desakan atau tarikan.

Kekuatan tanah tergantung pada gaya gaya yang bekerja diantara butir - butirnya. Kohesi tanah merupakan fungsi dari interaksi gaya tarik - menarik antara partikel. Bersama dengan sudut geser dalam, kohesi merupakan parameter kuat geser tanah yang menentukan ketahanan tanah terhadap deformasi akibat tegangan yang bekerja pada tanah. (Lynda, 2013)

Kekuatan geser tanah dapat dianggap terdiri dari dua bagian atau komponen, yaitu :

- Gesekan dalam, yang sebanding dengan tegangan efektif yang bekerja pada bidang geser.

- Kohesi yang tergantung pada jenis tanah dan kepadatannya tanah.

Teori Mohr (1910) dalam Hardiyatmo (2002) mengungkapkan bahwa keruntuhan suatu bahan dapat terjadi oleh akibat adanya kombinasi bahan kritis dari tegangan normal dan tegangan geser. Hubungan fungsi antara tegangan normal dan tegangan geser pada bidang runtuhnya, dinyatakan menurut persamaan :

$$
\tau=f(\sigma)
$$

Akibat adanya beban vertikal dan horizontal yang bekerja pada alat akan menyebabkan terjadinya tegangan pada tanah. Tegangan tersebut berupa tegangan utama besar dan tegangan utama kecil yang dapat menyebabkan tanah mengalami tegangan geser yang membentuk sudut terhadap bidang 
gesernya.Sedangkan tegangan utama sedang tetap bekerja merata disemua sisi tetapi tidak diperhitungkan karena tidak menyebabkan deformasi. (Nurdian, 2015)

Coulomb 1773 mendefinisikan hubungan fungsi antara tegangan normal $(\sigma)$ dan tegangan geser $(\tau)$ sebagai berikut :

$$
\tau=c+\sigma \tan \varnothing
$$

dengan :

$\tau$ : kekuatan geser tanah $\left(\mathrm{kg} / \mathrm{cm}^{2}\right)$,

$\sigma$ : tegangan normal tanah $\left(\mathrm{kg} / \mathrm{cm}^{2}\right)$,

$\emptyset$ : sudut geser dalam (derajat, ${ }^{0}$ ),

$c$ : kohesi tanah $\left(\mathrm{kg} / \mathrm{cm}^{2}\right)$.

\subsection{Stabilisasi Tanah}

Stabilisasi tanah merupakan suatu upaya untuk memperkuat atau menambahkan kapasitas dukung tanah agar tanah tersebut sesuai dengan persyaratan dan memiliki mutu yang baik.Tanah lempung merupakan salah satu jenis tanah yang sering dilakukan proses stabilisasi. Hal ini disebabkan sifat lunak plastis dan kohesif pada tanah lempung disaat basah.Sehingga menyebabkan perubahan volume yang besar. Sifat inilah yang menjadi alasan perlunya dilakukan proses stabilisasi agar sifat tersebut diperbaiki sehingga dapat meningkatkan daya dukung tanah tersebut.

Menurut Bowles (1993) menyatakan bahwa stabilisasi tanah mungkin dilakukan dengan cara sebagai berikut :

1. Meningkatkan kepadatan tanah.

2. Menambahkan bahan - bahan inert untuk meningkatkan kohesi dan kekuatan geser dari tanah.

3. Menambahkan bahan - bahan yang mampu mengakibatkan perubahan secara kimiawi ataupun fisik dari tanah.

4. Memperendah permukaan air tanah.

5. Memindahkan atau mengganti tanah yang bersifat buruk tersebut.

Stabilisasi dapat dibagi menjadi 3 jenis yaitu: stabilisasi mekanis, stabilisasi fisik, dan stabilisasi kimiawi. Stabilitas tanah lempung yang murah dan efektif adalah dengan menambahkan bahan kimia tertentu, dengan penambahan bahan kimia dapat mengikat mineral lempung menjadi padat, sehingga mengurangi kembang susut tanah lempung.

Kelebihan stabilisasi dengan menggunakan bahan tambahan (admixtures) adalah sebagai berikut :

a. Meningkatkan kekuatan tanah

b. Mengurangi deformasi

c. Menjaga stabilitas volume d. Mengurangi permeabilitas

e. Meningkatkan durabilitas

Biasanya suatu tanah lempung dapat diperkirakan akan mempunyaiperubahan isi yang besar (mengembang), apabila lndeks Plastisitas: PI >20.

Menurut Ingels dan Metcalf (1992), stabilisasi kapur dapat mengubah tanah menjadi gumpalan - gumpalan partikel.Banyaknya kapur yang digunakan berkisar antara $5-10 \%$, yang menghasilkan konsentrasi ion kalsium lebih besar dari yang diperlukan sebenarnya.

Metode atau cara memperbaiki sifat - sifat tanah ini juga sangat bergantung pada lama waktu pemeraman, hal ini disebabkan karena didalam proses perbaikan sifat - sifat tanah terjadi proses kimia yang dimana memerlukan waktu untuk zat kimia yang ada didalam aditif untuk bereaksi. Pada penelitian ini peneliti mencoba melakukan stabilisasi tanah dengan menggunakan bahan aditif yaitu kapur dimana komposisi kimia yang terkandung dalam kapur yaitu $\mathrm{CaO}$ yang dapat bereaksi dengan mineral tanah.

\subsection{Kapur}

Kapur adalah salah satu bahan yang dipakai untuk stabilisasi tanah.Bahan ini mudah didapat karena banyak dipasaran dan diproduksi secara besar -besaran.Kapur merupakan hasil endapan kerangka binatang yang hidup di lautan dan berlangsung hingga jutaan tahun.Untuk tujuan perbaikan tanah, bentuk kapur yang banyak digunakan adalah Kapur Tohor (CaO) dan Kapur Hidrasi atau Kapur Padam. Kapur $\mathrm{CaO}$ berasal dari pembakaran batu kapur/ batu gamping (lime stone), yang memiliki rumus kimia $\mathrm{CaCO}_{3}$ dengan reaksi kimia :

$$
\mathrm{CaCO}_{3} \rightarrow \mathrm{CaO}+\mathrm{CO}_{2}
$$

Disamping itu dikenal pula kapur padam (slaked lime), yang merupakan hasil pemadaman kapur tohor dengan air, dengan reaksi :

$$
\mathrm{CaO}+\mathrm{H}_{2} \mathrm{O} \rightarrow \mathrm{Ca}(\mathrm{OH})_{2}
$$

Hariman (2013), Reaksi tanah - kapur yang terjadi mencakup terjadinya kontak antara mineral lempung dengan bahan kapur, terjadi pertukaran ion dan kemudian terbentuklah suatu gel kalsium silica yang tak akan teruraikan dengan air sehingga terjadilah proses penggumpalan (flocculation). Tahap selanjutnya gel silica akanmenyelubungi dan mengikat tanah lempung serta menutupi pori - 


\section{Pengaruh Kapur Terhadap Kuat Geser Tanah Lempug}

pori tanah. Pada suatu saat gel akan mengkristal membentuk hidrasi kalsium silica dan kristal - kristal kecil ini dapat saling mengikat satu dengan yang lain, proses ini dapat disebut dengan sementasi. Sementasi merupakan faktor utama yang menyumbangkan kekuatan pada tanah yang terstabilisasi, tetapi proses sementasi dibatasi atau dikontrol oleh jumlah silica yang terkandung dalam tanah.

Kapur yang akan digunakan untuk perbaikan tanah, disarankan berupa bubuk. Hal ini sangat penting untuk proses hidrasi serta dapat mengurangi masalah yang timbul.

\section{Metodologi}

Pada Penelitian ini melakukan Metode Experimental di Laboratorium Mekanika Tanah Universitas Negeri Medan dengan menggunakan tanah lempung dari Tarutung Sibolga Km.11, Desa Banuaji II, Kecamatan Adiankoting, Tapanuli Utara. Adapun Alur penelitiannya sebagaimana ditunjukkan gambar 1 dibawah ini:

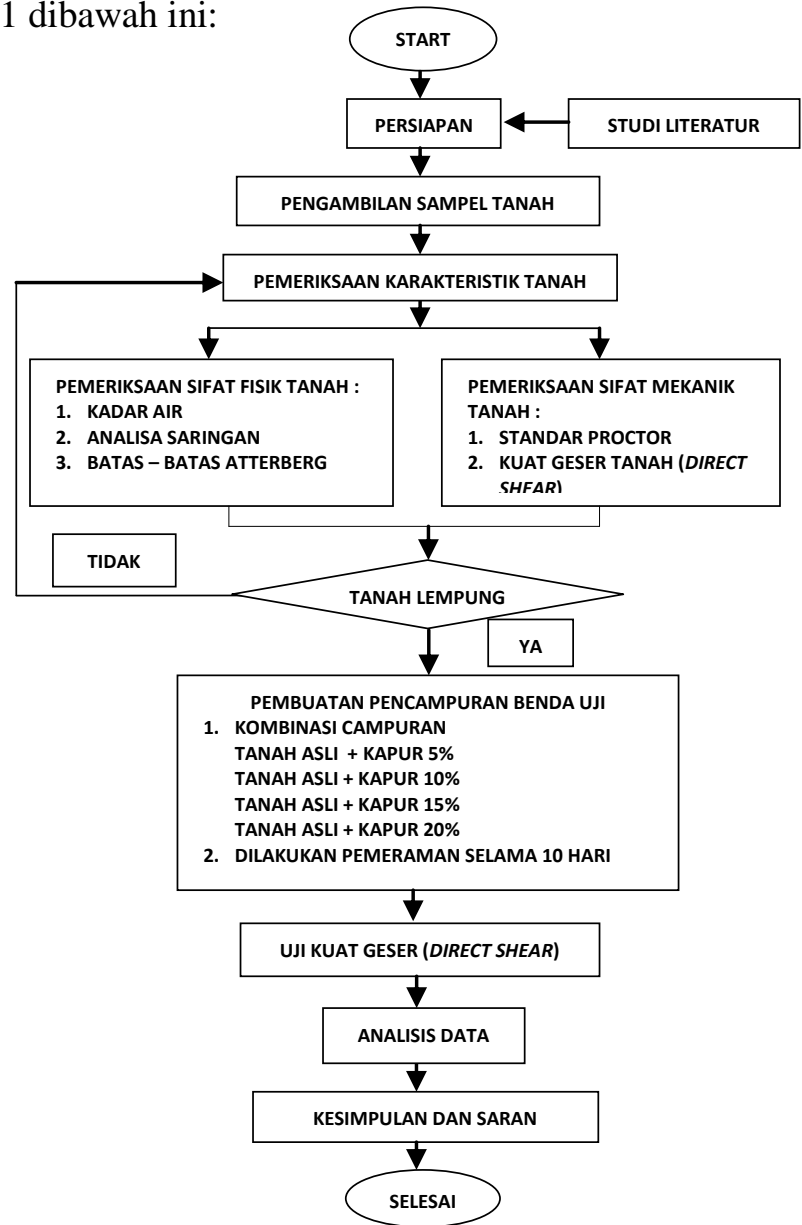

Gambar 1. Diagram Alir Penelitan
4 Hasil dan Pembahasan

4.1 Pengujian Analisa Saringan Tanah Asli

Untuk mengetahui komposisi dari butiran suatu tanah dapat dilihat dengan cara melakukan pengujian analisa saringan. Grafik dari hasil percobaan analisa saringan dapat dilihat pada Gambar 2 berikut ini :

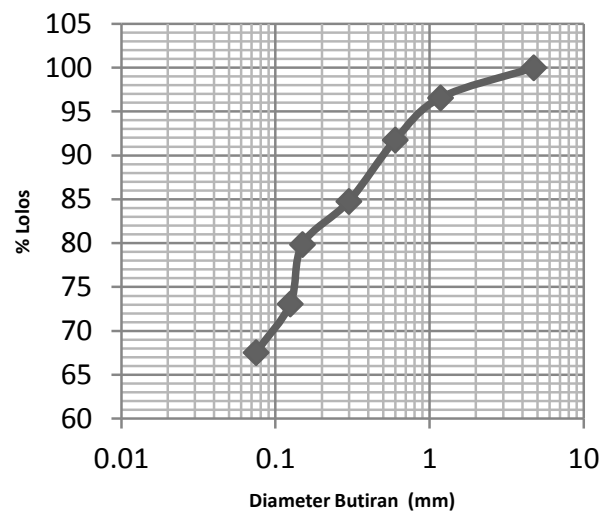

Gambar 2. Grafik Anlisa Saringan

Berdasarkan data dari analisis saringan yang dilakukan, maka dapat di analisis melalui kurva distribusi bahwa klasifikasi tanah berdasarkan USCS, dapat dikelompokkan tanah berbutir halus $>50 \%$ melalui ayakan 200 adalah sebesar $67.55 \%$

\subsection{Pengujian Kepadatan Standar}

Pengujian pemadatan standar bertujuan untuk menentukan hubungan antara kadar air dan kepadatan tanah dengan cara memadatkan tanah didalam silinder berukuran tertentu menggunakan cetakan, sampel tanah lolos saringan No.40. Kegunaan pengujian proctor standar untuk mencari nilai kepadatan

maksimum dan kadar air optimum dari suatu sampel tanah. Hasil pengujian proctor standar dilihat Gambar 2. sebagai berikut:

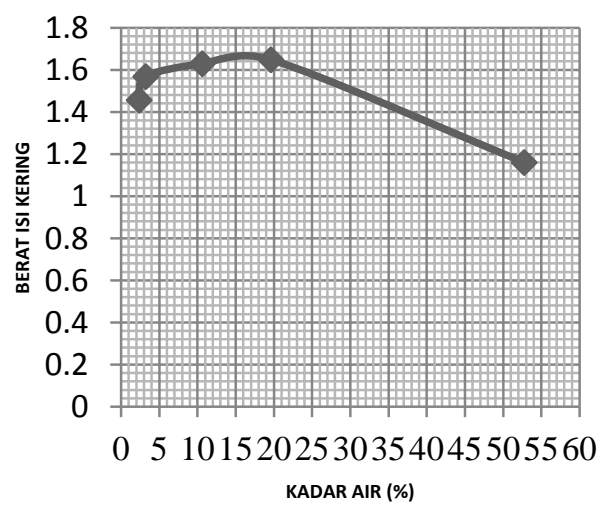

Gambar 3. Kurva Hubungan Kadar Air Dengan Berat Volume Tanah Kering 


\section{Nahesson Panjaitan}

Dari hasil kurva hubungan kadar air dengan berat voume tanah kering didapatkan bahwa kadar air optimum 16,2\% dan berat kepadatan kering 1,67 gr/cm.

\subsection{Pengujian Uji Geser Pada Pencampuran Tanah Dengan Kapur}

Pada penelitian ini, pengujian kuat geser dilakukan untuk mengetahui tegangan geser $(\tau)$ dan tegangan normal $(\sigma)$ pada tanah sehingga didapat nilai kuat geser dalam $(\emptyset)$ dan nilai kohesi (c) pada tanah yang dicampurkan pada kadar kapur 5\%,10\%, 15\%, dan 20\%. Berikut hasil nilai dari pengujian kuat geser setelah distabilisasi dengan kapur dengan hasil sebagai berikut :
Tabel 2a. Pengujian Kuat Geser Dalam pemeraman 10 Hari untuk persentase kapur $0-5 \%$

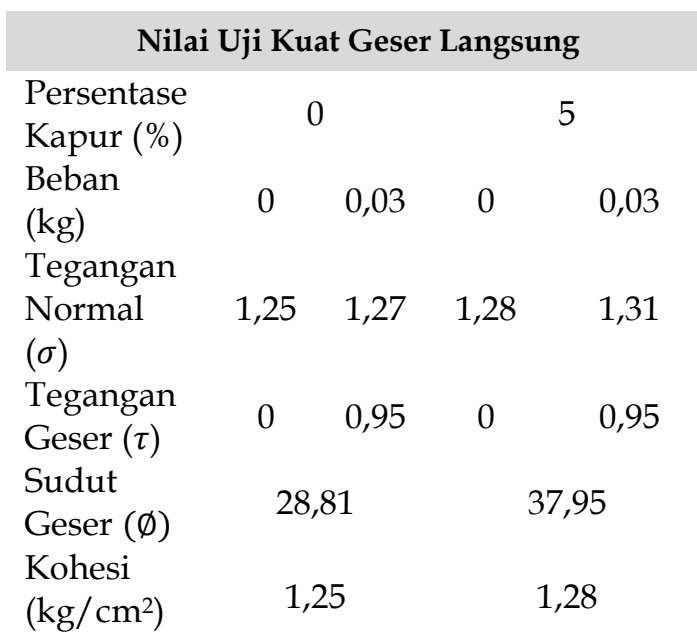

Tabel 2b. Pengujian Kuat Geser Dalam pemeraman 10 Hari untuk persentase kapur $10-15 \%$

Nilai Uji Kuat Geser Langsung

\begin{tabular}{lcrrr}
$\begin{array}{l}\text { Persentase } \\
\text { Kapur }(\%)\end{array}$ & \multicolumn{2}{c}{10} & \multicolumn{2}{c}{15} \\
$\begin{array}{l}\text { Beban } \\
(\mathrm{kg})\end{array}$ & 0 & 0,95 & 0 & 0,95 \\
$\begin{array}{l}\text { Tegangan } \\
\text { Normal }\end{array}$ & 0 & 0,03 & 0 & 0,03 \\
$(\sigma)$ & & & & \\
Tegangan & 1,29 & 1,33 & 1,36 & 1,41 \\
$\begin{array}{l}\text { Geser }(\tau) \\
\text { Sudut }\end{array}$ & 47,46 & & 51,34 \\
$\begin{array}{l}\text { Geser }(\varnothing) \\
\text { Kohesi } \\
\left(\mathrm{kg} / \mathrm{cm}^{2}\right)\end{array}$ & 1,29 & & 1,36
\end{tabular}

Tabel 2c. Pengujian Kuat Geser Dalam pemeraman 10 Hari untuk persentase kapur $20 \%$

\begin{tabular}{lcc}
\multicolumn{3}{c}{ Nilai Uji Kuat Geser Langsung } \\
Persentase Kapur $(\%)$ & \multicolumn{2}{c}{20} \\
Beban $(\mathrm{kg})$ & 0 & 0,95 \\
Tegangan Normal $(\sigma)$ & 0 & 0,03 \\
Tegangan Geser $(\tau)$ & 1,44 & 1,51 \\
Sudut Geser $(\varnothing)$ & & 63,77 \\
Kohesi $\left(\mathrm{kg} / \mathrm{cm}^{2}\right)$ & & 1,44
\end{tabular}

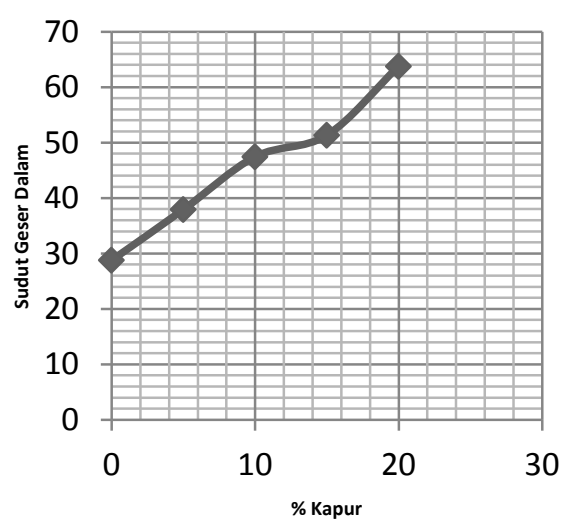

Gambar 4. Hubungan Antara Persentase Kapur Dengan Nilai Kuat Geser Dalam Pemeraman 10 Hari

Dari hasil pengujian tanah dengan penambahan kapur yang dapat dilihat pada Tabel 2a,2b dan 2c menunjukan bahwa terjadinya peningkatan maksimum nilai sudut geser dalam terjadi pada kapur 20\% sebesar $63,77^{\circ}$. Peningkatan nilai sudut geser disebabkan karena perubahan reaksi antara partikel tanah dengan butiran kapur.Dimana kapur memiliki daya ikat dan menurunkan sifat sensitif terhadap air dan juga memiliki butiran yang halus dan unsurnya saling mengikat dengan partikel lainnya. Sehingga dapat menyerap air karena kepadatan porinya rendah dan berongga, sehingga mengurangi kadar air dalam tanah dan membuatnya menjadi lebih padat .Oleh karena itu dapat meningkatkan kerapatan tanah sehingga nilai kohesi tanah atau sudut geser meningkat.(Panjaitan, 2015)

\section{Simpulan dan Saran}

\subsection{Simpulan}

Bedasarkan hasil penelitian yang telah dilakukan, dapat diambil simpulan sebagai berikut :

1) Berdasarkan hasil uji sifat fisis tanah asliTarutung Sibolga Km.11, Desa Banuaji 
II, Kecamatan Adiankoting, Tapanuli Utara, menurut United Soil Classification System, tanah lempung Tarurutng Sibolga termasuk dalam kelompok OL atau tanah berbutir halus $>50 \%$ melalui ayakan 200 adalah sebesar $67.55 \%$ yaitu termasuk lempung berlanau organik dengan plastisitas rendah dan mempunyai potensial pengembangan yang rendah.

2) Nilai maksimum uji geser langsung terjadi pada penambahan kapur $20 \%$ yaitu penambahan 5\% kapur nilai kohesi dan sudut geser masing - masing sebesar 1,28 $\mathrm{kg} / \mathrm{cm}^{2}$ dan $37,95^{\circ}$, meningkat menjadi 1,44 $\mathrm{kg} / \mathrm{cm}^{2}$ dan 63,770 pada pencampuran kapur 20\%.. Peningkatan nilai kuat geser disebabkan oleh kadar air dan kepadatan serta lama pemeraman juga memperbaiki nilai uji geser langsung karena dengan adanya pemeraman maka akan menyebabkan tanah dengan kapurdapat bereaksi lebih baik.

\subsection{Saran}

Melihat hasil dari penelitian ini perlu dilakukan penelitian lebih lanjut dengan memperhatikan hal-hal sebagai berikut :

1) Untuk penelitian selanjutnya perlu adanya penambahan pencampuran kapur sehingga mendapatkan nilai kuat geser yang optimum.

2) Untuk pengujian geser, perlu adanya variasi penambahan beban pada uji geser guna mendapat data yang lebih lengkap.

\section{Daftar Pustaka}

Bowles, J. E. 1991. Analisa dan Desain Pondasi. Edisi keempat Jilid 1. Jakarta: Erlangga

Bowles, J.E. 1993. Sifat - sifat Fisis dan Geoteknis Tanah (Mekanika Tanah). Jakarta: Erlangga.

Craig, R.F,. S, Budi Susilo. 1989. Mekanika Tanah. Jakarta: Erlangga

Das, Braja M. 1995. Mekanika Tanah (Prinsip prinsip Rekayasa Geoteknis). Jakarta: Erlangga

Grim, R.E. 1953. Clay Mineralogy. New York: Mc.Graw-Hill Book Company.

Hardiyatmo, Hary Christady. 2002. Mekanika Tanah 1. Yogyakarta: Gadjah Mada University Press

Hariman Palar S,. Monintja, Turangan. 2013. Pengaruh Pencampuran Tras Dan Kapur Pada Lempung Ekspansif Terhadap Nilai Daya
Dukung. Jurnal Sipil Statik, Vol.1, No.6: 390-399

Holtz, R.D,. Kovacs, W.D. 1981, “An Introduction in Geotechnical Engineering, Prentice Hall Civil Engineering ang Engineering Mechanic Series.

Ingles, O.G,. Metcalf, J.B. 1992. Soil Stabilitzation Principles and Practice. Butterworths Pty, Limited. Melbourne.

Lynda, Angelina. 2013. Karakteristik Kuat Geser Tanah Dengan Metode Stabilisasi Biogrouting Bakteribacillus Subtilis. Fakultas Teknik Universitas Hasanuddin Makassar

Nurdian, Syahreza,. Setyanto,. Afriani, Lusmeilia. 2015. Korelasi Parameter Kekuatan Geser Tanah Dengan Menggunakan Uji Triaksial Dan Uji Geser Langsung Pada Tanah Lempung Substitusi Pasir. JRSDD, Vol. 3, No. 1, Hal:13 - 26

Panjaitan, Nahesson H, Sinuraya, Arwadi. 2015. Cation Exchanges on Stabilized Soft Clay Using Electrokinetic Process. IOSR Journal of Engineering (IOSRJEN).Vol. 05, Issue 11: 10-15

Santosa, Budi,. Suprapto, Heri,. HS, Suryadi. 1998. Dasar Mekanika Tanah. Jakarta: Gunadarma.

Terzaghi, Karl,. Ralph, Peck. 1987. Mekanika Tanah Dalam Praktek Rekayasa Jilid 1. Jakarta: Erlangga. 